\title{
Growth behavior of small surface cracks in coarse and ultrafine grained copper
}

\author{
M. Goto ${ }^{1}$, S. Z. $\operatorname{Han}^{2}$, Y. Ando ${ }^{1}$, N. Kawagoishi ${ }^{3}$, \\ N. Teshima ${ }^{4} \&$ S. S. Kim ${ }^{5}$ \\ ${ }^{I}$ Department of Mechanical Engineering, Oita University, Japan \\ ${ }^{2}$ Korea Institute of Materials Science, Republic of Korea \\ ${ }^{3}$ Department of Mechanical Engineering, Kagoshima University, Japan \\ ${ }^{4}$ Department of Mechanical Engineering, \\ Oita National College of Technology, Japan \\ ${ }^{5}$ Engineering Research Center, \\ Gyeongsang National University, Republic of Korea
}

\begin{abstract}
Since fatigue life of a plain specimen of ductile metals is controlled mainly by the propagation life of a small surface crack, to clarify the growth behavior of a small crack is crucial to the safe design of smooth members. However, little has been reported on the growth behavior of small surface cracks in ultrafine grained (UFG) metals. In the present study, stress-controlled fatigue tests for coarse grained (CG) and UFG copper were conducted. The surface damage evolution during cyclic stressing was observed by optical microscopy, and the growth behavior of a small surface crack was monitored by a plastic replication technique. The physical background of fatigue damage for CG and UFG copper was discussed from the viewpoints of the initiation and growth behavior of small surface cracks.
\end{abstract}

Keywords: equal channel angular pressing, copper, ultrafine grain, fatigue, small surface-crack.

\section{Introduction}

Copper has been widely used as a base material in various electronics-based industries. Recent developments in electronic apparatus however mean that 
higher strength/ductile materials are now required to meet these needs. To improve the strength of copper requires the development of highly alloyed $\mathrm{Cu}$ materials. Alloyed $\mathrm{Cu}$ however, possesses inherently lower conductivity compared to their unalloyed counterparts. Therefore, in order to overcome this inherent shortcoming associated with conventional $\mathrm{Cu}$ alloys, the development of pure $\mathrm{Cu}$ with submicron grained structure is currently being explored by employing a severe plastic deformation principle, such as the ECAP (equal channel angular pressing) processing [1-4].

For applying the ultrafine grained (UFG) copper to the components of machines and structures, fatigue damage should be clarified. Since the fatigue life of machine components and structures are mainly controlled by the growth life of a fatigue crack, the crack growth behavior should be clarified for the design of safe machine components and structures. Recently, the growth behaviors of millimeter-range cracks in UFG metals were studied for compacttension [5-7] and single edge-notched specimens $[8,9]$. On the other hand, the fatigue life of smooth specimens is approximately controlled by the growth life of a small surface crack. Nisitani and Goto [10], Goto and Nisitani [11] and Goto and Knowles [12] showed that the crack growth life from an initial size to $1 \mathrm{~mm}$ accounted for about $70 \%$ of the fatigue life of plain specimens of many conventional grain-sized metals. This means that the growth behavior of small cracks must be clarified to estimate the fatigue life of plain members. For both coarse grained (CG) and UFG copper, to the authors' knowledge, there has been little reported in the literature on the growth behavior of a small surface crack [13].

In the present study, stress-controlled fatigue tests for CG and UFG copper were conducted. The surface damage evolution during cyclic stressing was observed by optical microscopy, and the growth behavior of a small surface crack was monitored using a plastic replication technique (PRT). The physical background of fatigue damage was discussed from the viewpoints of the initiation and growth behavior of small surface cracks.

\section{Experimental procedures}

The material used was $99.99 \%$ pure oxygen-free copper. Before the ECAP process, the material was annealed at $500^{\circ} \mathrm{C}$ for $1 \mathrm{hr}$. In ECAP die, the inner and outer angles of channel intersection were 90 and $45^{\circ}$, respectively. Repetitive ECAP was accomplished by $\mathrm{Bc}$ route (after each pressing, the billet bar was rotated around its longitudinal axis through $90^{\circ}$ ). Four passages of extrusion resulted in an equivalent shear strain of about 3.9 [14]. $\mathrm{MoS}_{2}$ was used as lubricant at each pressing, and the pressing speed was $5 \mathrm{~mm} / \mathrm{sec}$. After ECAP, the microstructure and mechanical properties were studied. Transverse cross sections of ECAP processed bars were cut to prepare specimens for transmission electron microscopic observation. Specimens were mechanically polished to a thickness of $100 \mu \mathrm{m}$, then subjected to twin-jet electropolishing. The solution was $200 \mathrm{ml} \mathrm{CH}_{3} \mathrm{OH}$ plus $100 \mathrm{ml} \mathrm{HNO}_{3}$. The jet thinning was conducted at $-30^{\circ} \mathrm{C}$. 
Round bar specimens of $5 \mathrm{~mm}$ diameter (Fig. 1) were machined from the annealed and ECAP processed bars. Although the specimens had a circumferential notch $(\rho=20 \mathrm{~mm}$ and $c=0.25 \mathrm{~mm}$, where $\rho=$ radius and $c=$ depth of the notch), the strength reduction factor for this geometry was close to one, and therefore the specimens could be considered plain specimens. Before testing, all the specimens were electropolished to remove about $25 \mu \mathrm{m}$ from the surface layer in order to facilitate observations of the surface state.

All tests were carried out at room temperature using a rotating bending fatigue machine operating at $3000 \mathrm{rev} / \mathrm{min}$. The surface damage evolution during cyclic stressing was observed by optical microscopy. The measurement of crack length was conducted using a PRT. The crack length, $l$, is a length measured along the circumferential direction of the surface. The stress value referred to in this paper is that of the nominal stress amplitude, $\sigma_{a}$, at the minimum cross-section.

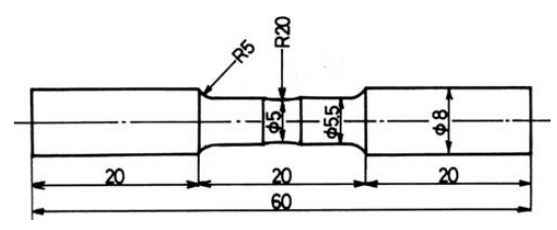

Figure 1: $\quad$ Shape of the specimen.

\section{Experimental results and discussion}

\subsection{Microstructure and mechanical properties of the materials}

Figure 2 shows typical microstructures for CG and UFG copper. Grain size of CG copper was about $100 \mu \mathrm{m}$. For UFG copper, refinement of structure is evident. Namely, granular grains with average size of $300 \mathrm{~nm}$ are formed, and grain boundary (GB) areas involve a high population of dislocations. The SADP (selected area diffraction patterns of the center area, $1 \mu \mathrm{m}$ in diameter) consists of rings of diffraction spots, showing that GBs have high angles of misorientation. The fraction of high angle GBs might be relatively low [15]. In addition, the GBs had lost their sharpness and exhibited a 'spotty' contrast and broad contours, suggesting non-equilibrium GBs contain random networks of GB dislocations [16].

The change in heat flow value was measured using a differential scanning calorimeter in a nitrogen environment with a ramping rate of $1.67^{\circ} \mathrm{C} / \mathrm{min}$ up to $500^{\circ} \mathrm{C}$. The measurements of the heat flow value showed that the changes in the heat flow value $(\mathrm{CHFV})$ after the 4 th pressing of ECAP were $C H F V=0.85 \mathrm{~J} / \mathrm{g}$. The rationale for the heat-flow measurement is that the heat-flow of pure copper would be solely controlled by the generation and/or annihilation of dislocations and GBs during ECAP processing, unlike the other alloys with either precipitation hardening or solid solution hardening mechanism. As might be expected, the $\mathrm{CHFV}$ of fully annealed copper is almost zero. The large value of 

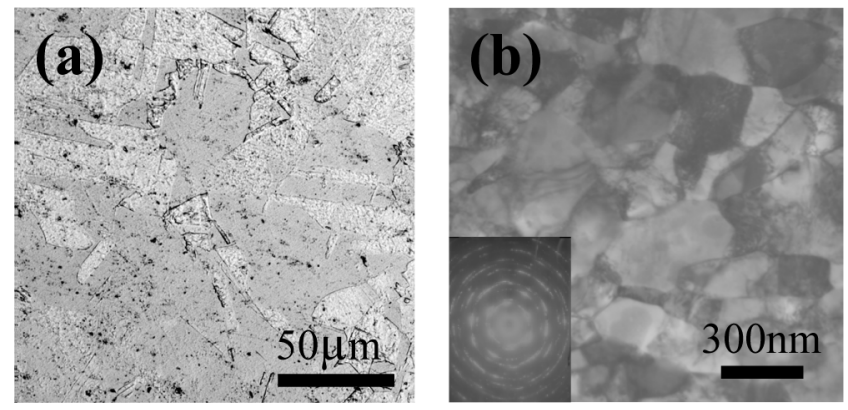

Figure 2: $\quad$ Microstructure of the materials; (a) CG copper, (b) UFG copper.
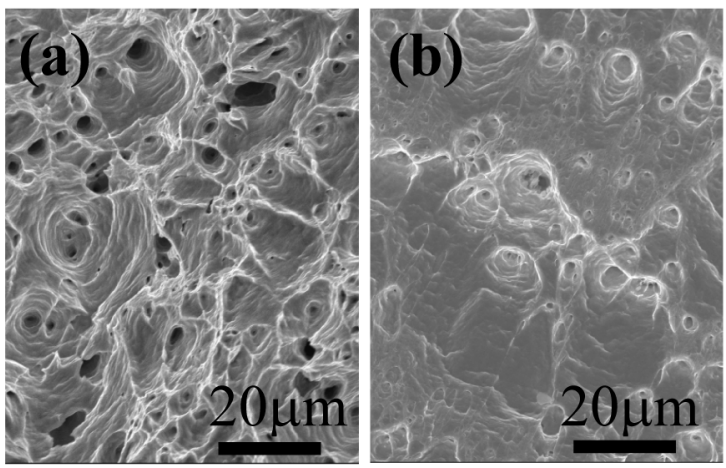

Figure 3: $\quad$ Fracture surface of tensile specimens; (a) CG copper, (b) UFG copper.

CHFV after the 4 th pressing of ECAP means that redundant strain energy related to high-density dislocations is stored in the material, showing instability of the microstructure.

The mechanical properties of an annealed bar were $183 \mathrm{MPa}$ tensile strength, $64 \%$ elongation, and a Vickers hardness number of 63 . After eight passages of ECAP, their values changed to $438 \mathrm{MPa}, 28 \%$, and 141 , respectively. The relationship between the Vickers hardness number, $H_{V}$, and the number of pressings showed that a dramatic increase in $H_{V}\left(H_{V}=63\right.$ to 128) occurs from the first pressing. However, the subsequent increases become milder, followed by a saturation trend after the 3rd pressing. Figures 3(a) and (b) show the postfracture surface for tensile specimens of CG and UFG copper, respectively. The fracture surface of CG copper shows many dimples. The sample processed by ECAP shows a flat fracture surface, including a couple of dimples, compared to the fracture surface of annealed sample. There is no significant difference in the dimple size between two samples, in spite of the two orders of magnitude difference in grain size. Nevertheless, the dimples are shallower for the UFG copper because of its decreased ductility. 


\subsection{Formation behavior of fatigue damage}

Figure 4 shows the S-N curve of $\mathrm{CG}$ and UFG copper. For UFG copper examined under stress controlled testing, the enhancement in fatigue life is obvious [17-19]. The degree of enhancement is sharply increased with increasing stress amplitude. In the long-life field in excess of $N=10^{7}$ cycles, however, the fatigue life to failure of UFG copper tends to coincide with that of CG copper.

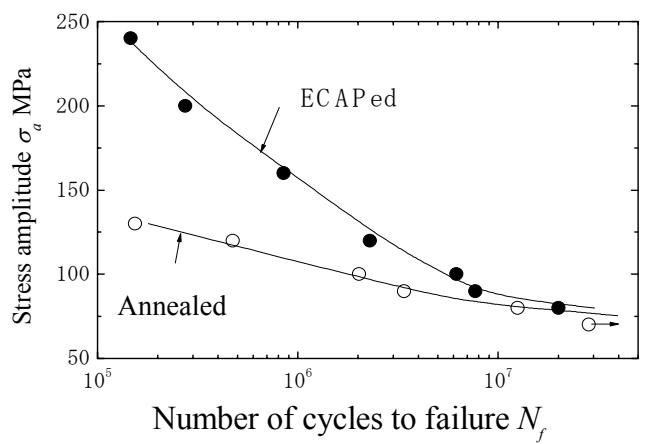

Figure 4: $\quad$ S-N curve.

Figures 5(a) and (b) show the typical surface damage of a post-fatigued specimen for CG and UFG copper, respectively. For CG copper, slip bands were formed along limited sip planes within a small number of grains and the length of slip bands was nearly equivalent to the grain size. In contrast, the surface of UFG copper was covered by a high population of damaged area. Figure 5(c) is SEM micrograph of the highlighted area in Fig. 5(b), showing protrusions and intrusions [20]. Surprisingly, those sizes are larger than the grain size.
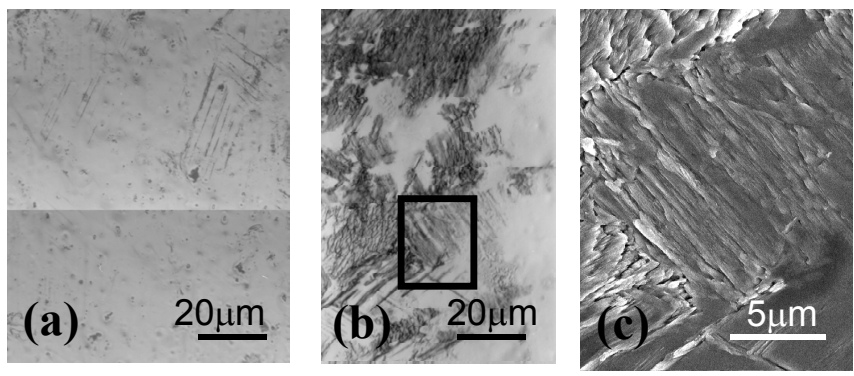

Figure 5: $\quad$ Surface morphology of post-fatigued specimen at $\sigma_{a}=120 \mathrm{MPa}$; (a) CG copper $\left(N_{f}=4.739 \times 10^{5}\right)$, (b) UFG copper $\left(N_{f}=3.75 \times 10^{6}\right)$,

(c) SEM micrograph of the highlighted area in (b).

Figure 6 shows the formation process of surface damage at $\sigma_{a}=120 \mathrm{MPa}$ for UFG copper, where the number of cycles to failure, $N_{f}$, was $N_{f}=3.75 \times 10^{6}$. It is 
found that there is a pronounced time lag in the onset of a significant enlargement of the damaged areas. In addition to this, the whole surface observations of the specimen indicated that the damaged regions were formed at an early stage of cycling, and that the number and area of these regions slowly increased with further cycling up to a specific number of cycles, depending on the material and stress amplitude. Once this specific number of cycles had been exceeded, both the number and area of the damaged regions showed a significant rise. The number of cycles performed prior to the start of this remarkably large extension in damaged regions was about half of fatigue life $\left(N \approx 1.7 \times 10^{6}\right)$.

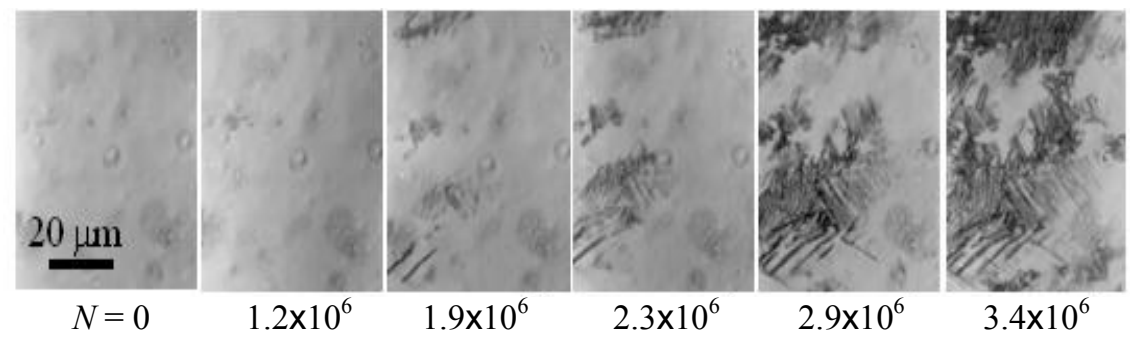

Figure 6: Change in surface state of UFG copper during repeated stressing of $\sigma_{a}=120 \mathrm{MPa}\left(N_{f}=3.75 \times 10^{6}\right)$.

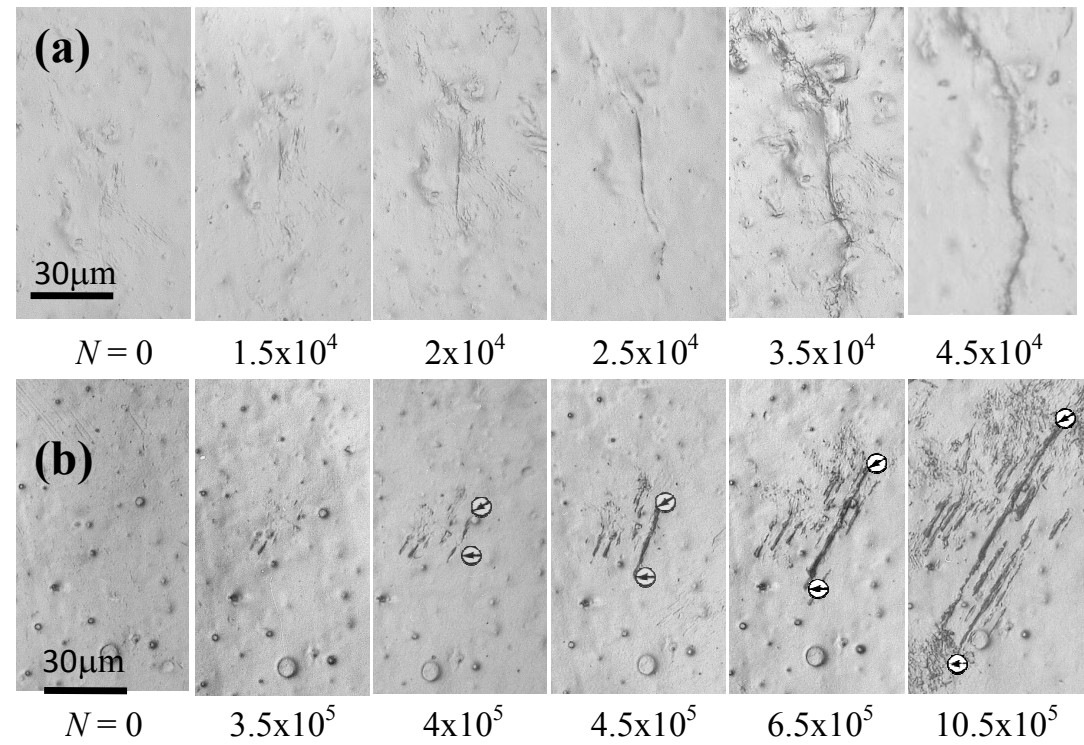

Figure 7: Change in surface state around a major crack observed by a plastic replication technique; (a) $\mathrm{CG}, \sigma_{a}=130 \mathrm{MPa}, N_{f}=1.535 \times 10^{5}$, (b) UFG, $\sigma_{a}=120 \mathrm{MPa}, N_{f}=2.3 \times 10^{6}$.

Figure 7 shows initial growth behavior from a major crack, which led to the final fracture of the specimen, monitored by PRT. At an early stage of cycling, 
for CG copper, slip bands were formed within a grain. A grain size crack was initiated from slip bands at an about $20 \%$ of fatigue life. For UFG copper, a 30 $\mu \mathrm{m}$ length crack was initiated at about $20 \%$ of fatigue life.

\subsection{Growth behaviour of a small crack}

Figure 8 shows the crack growth curve $(\ln l$ vs. $N$ relation). The relationship for UFG copper can be approximated by a straight line independent of a stress amplitude. For CG copper, however, the relationship depends on a stress amplitude. Namely, the growth curves at a stress above $\sigma_{a}=100 \mathrm{MPa}$ are nearly represented by a straight line. At a stress below $\sigma_{a}=90 \mathrm{MPa}$, a linear relation of the growth curve nearly holds for a crack length in excess of $l=0.3 \mathrm{~mm}$, whereas, each plot for $l<0.3 \mathrm{~mm}$ deviates upward from an extension of the linear relation for $l>0.3 \mathrm{~mm}$.
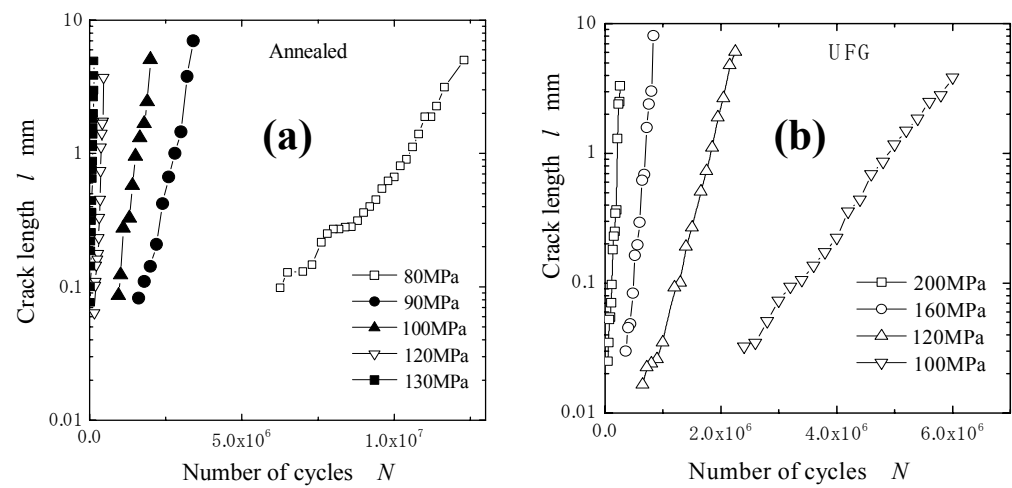

Figure 8: $\quad$ Crack growth curve ( $\ln l$ vs $N$ relation); (a) CG copper, (b) UFG copper.

The linear relation shown in Fig. 8 means that crack growth rate (CGR, $d l / d N)$ should be proportional to $l$ at a constant stress amplitude. Figure 9 shows the CGR versus crack length relation. The CGR for CG copper is nearly proportional to the crack length $(d l / d N \propto l)$ with the exception of the CGR below $d l / d N=10^{-6}$ $\mathrm{mm} / \mathrm{c}$. For UFG copper, however, the $d l / d N \propto l$ relation nearly holds even for extremely low CGR range $\left(d l / d N<10^{-6} \mathrm{~mm} / \mathrm{c}\right)$ in spite of some fluctuating plots around $d l / d N=10^{-8} \mathrm{~mm} / \mathrm{c}$. To compare the growth resistance of a small crack between CG and UFG copper, the relations at $\sigma_{a}=80$ and $120 \mathrm{MPa}$ for CG copper (Fig. 9(a)) were redrawn by dashed lines in Fig. 9(b). The comparison of the relation at $\sigma_{a}=120 \mathrm{MPa}$ for both copper indicates that CGR of CG copper is about three times larger than that of UFG copper. In addition, relation at $80 \mathrm{MPa}$ for CG copper is nearly equivalent to that at $85 \mathrm{MPa}$ for UFG copper. These are different from the growth behavior of other ECAPed Al and steel alloys, in which finer microstructures exhibit higher growth rates [5, 6, 8]. However, 
experiments conducted by other alloys were for a long crack initiated from artificial notches. This means that applied stress amplitudes were sufficiently small and a crack propagated under the small scale yielding condition. In the present fatigue tests, the stress amplitudes were excessively large compared to stresses applied to other alloys. For CG copper, especially, the ratios of stress amplitude to tensile strength, $\sigma_{a} / \sigma_{u}$, were 0.43 and 0.66 for $\sigma_{a}=80$ and $120 \mathrm{MPa}$, respectively. Accordingly, the crack at $\sigma_{a}=120 \mathrm{MPa}$ propagates under large scale yielding, showing accelerated CGR compared to UFG copper with higher tensile strength.

The dependency of CGR on stress amplitude was studied and it showed that $d l / d N$ is nearly proportional to $\sigma_{a}^{n}$ at a constant crack length. The value of $n$ was about 7.5 and 4.4 for CG and UFC copper, respectively. Considering the stress dependency and the relation $(d l / d N \propto l)$ in Fig. 9 together, thus, the CGR of the present copper is uniquely determined by a term $\sigma_{a}^{n} l$, namely small-crack growth law (SCGL) defined by equation (1) holds [10, 21];

$$
\frac{\mathrm{d} l}{\mathrm{~d} N}=C_{1} \sigma_{a}^{n} l
$$
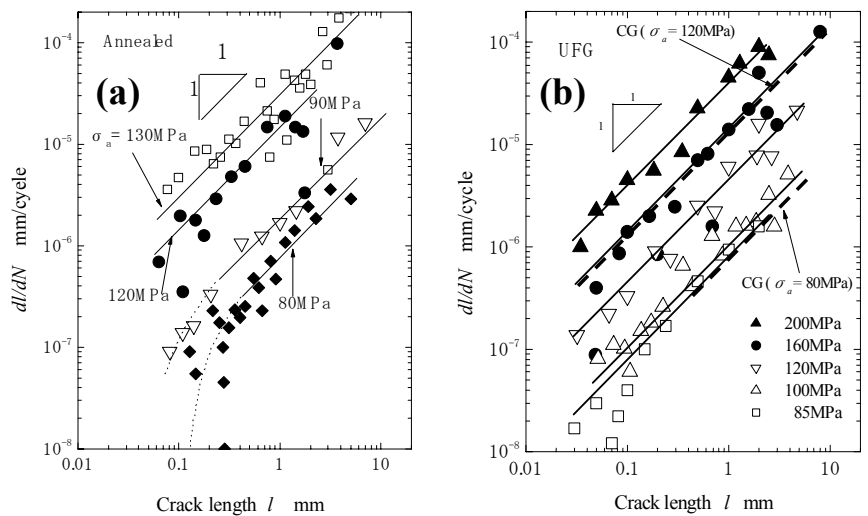

Figure 9: $\quad$ Crack growth data ( $d l / d N$ vs $l$ relation); (a) CG copper, (b) UFG copper.

Figure 10 shows the $d l / d N$ versus $\sigma_{a}^{n} l$ relation. It is evident that the SCGL is available for estimating CGR of a small surface crack propagating with a growth rate above $10^{-6}$ and $10^{-7} \mathrm{~mm} / \mathrm{c}$ for CG and UFG copper, respectively. A dashed line in Fig. 10(b) is the relationship obtained from UFG copper processed by twelve pressing cycles of ECAP (grain size: $300 \mathrm{~nm}$ ). There is no significant deference of the relationship between UFG copper with four and twelve ECAP process cycles.

Many researchers have reported that the growth rate of fatigue cracks can be unified in terms of the stress intensity factor range $\Delta K$. Here, the parameter $\Delta K$ is 
the effective parameter for a crack when the condition of small scale yielding at a crack tip is satisfied. The value of $\Delta K$ for an infinite plate with a crack is given by the equation $\Delta K=\Delta \sigma(\pi a)^{1 / 2}$. This equation indicates that the stress range has to be higher for a small crack in order to get the same growth rate as for a larger crack. Therefore, when a sufficiently small crack propagates at a finite growth rate (for example, $10^{-6}$ to $10^{-3} \mathrm{~mm} / \mathrm{c}$ ) the condition of small scale yielding is not usually satisfied. Thus the growth rate of a small crack cannot be determined uniquely by $\Delta K$. Nisitani and Goto showed that a term $\sigma_{a}{ }^{n} l$ is effective parameter to determine the CGR of a small crack in many ductile materials. Here, $n$ is a material constant. The expression $\sigma_{a}{ }^{n} l(n=3)$ was first proposed by Frost and Dugdale [22]. They applied it to comparatively large cracks in which the condition of small scale yielding nearly holds. Now $\sigma_{a}^{3} l$ can be considered as an approximation for $\Delta K$, whereas $\sigma_{a}{ }^{n} l$ in the present study is a parameter for crack propagation under large scale yielding. Moreover, an effective and convenient method based on a SCGL in which the effect of mechanical properties is partly considered has been proposed for predicting the fatigue life of smooth members of many CG metals [23, 24]. The prediction was in good agreement with the experimental results. Thus, Fig.10(b) means an applicability of SCGL to the evaluation of fatigue life of UFG metals.
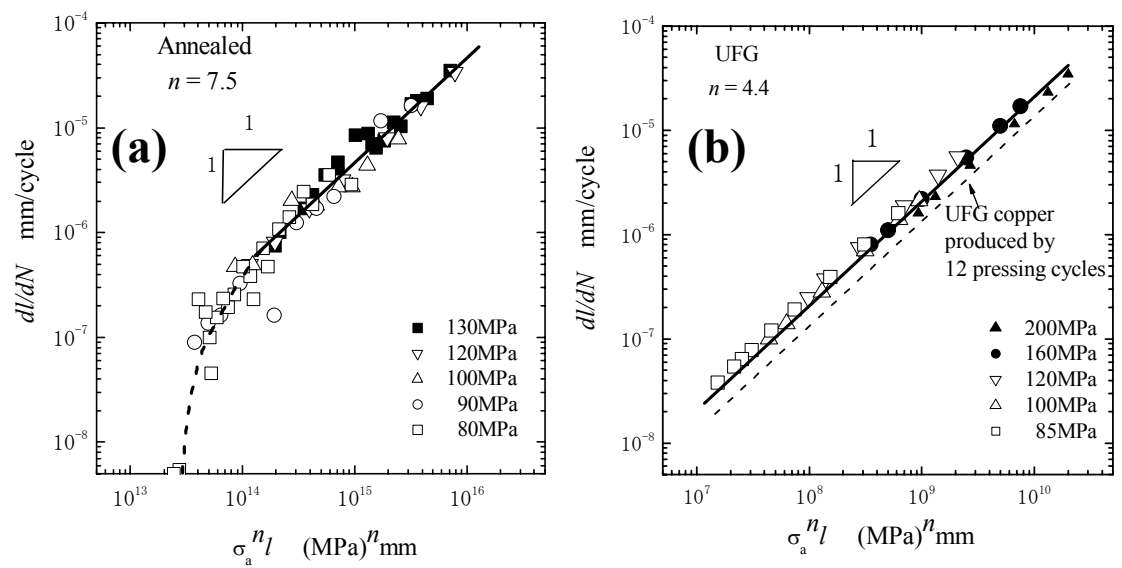

Figure 10: $\quad d l / d N$ vs. $\sigma_{a}{ }^{n} l$ relation; (a) CG copper $(n=7.5)$, (b) UFG copper ( $n=4.4$, dashed line indicates the relation for UFG copper processed by 12 pressing cycles).

\section{Conclusions}

The main results of the present study can be summarized as follows:

(1) The enhancement in fatigue life due to ECAP was remarkably large in the short-life regime, yet not so pronounced in the long-life regime, as reflected by the fatigue strength of UFG copper at $N=10^{7}$ cycles, $\sigma_{w}$, which coincided with that of fully annealed CG copper. 
(2) For CG copper, a major crack, which led to the final fracture of the specimen, was initiated form slip bands with a dimension of grain size. For UFG copper, it was initiated from intrusions with a dimension of over ten times grain sizes. For both copper, the crack growth life from an initial size to fracture accounted for about $80 \%$ of the fatigue life of plain specimens.

(3) At a high stress amplitude $\left(\sigma_{a}>100 \mathrm{MPa}\right)$, growth rate of a small crack of $\mathrm{CG}$ copper was larger than that of UFG copper. At $\sigma_{a}=80 \mathrm{MPa}$, however, CGR of CG copper was nearly equivalent to that of UFG copper. In CG copper, the ratio of $\sigma_{a}=100 \mathrm{MPa}$ to tensile strength was about 0.55 . In a range of $\sigma_{a}>100 \mathrm{MPa}$, thus, the crack in CG copper propagates under large scale yielding, showing accelerated CGR compared to UFG copper with higher tensile strength.

(4) The growth rate of a small crack cannot be unified in terms of the stress intensity factor range $\Delta K$, but it was uniquely determined by a term $\sigma_{a}{ }^{n} l$. Here, $n$ is a material constant and the value of $n$ was about 7.5 and 4.4 for CG and UFG copper, respectively. For CG copper, the term could estimate the growth rate of a crack propagating with $d l / d N>10^{-6} \mathrm{~mm} /$ cycle. For UFG copper, the term was applicable to a crack with an extremely low growth rate $\left(d l / d N>10^{-7} \mathrm{~mm} /\right.$ cycle $)$.

\section{Acknowledgement}

This study was supported by a Grant-in-Aid (20560080) for Scientific Research (C) from the Ministry of Education, Science and Culture of Japan as well as a grant from the Fundamental R\&D Program for Core Technology of Materials funded by the Ministry of Commerce, Industry and Energy, Republic of Korea.

\section{References}

[1] Segal, V.M., Materials processing by simple shear. Mater Sci Eng, A197, pp.157-164, 1995.

[2] Valiev, R.Z., Structure and mechanical properties of ultrafine-grained metals. Mater Sci Eng, A234-236, pp.59-66, 1997.

[3] Zhu, Y.T. \& Lowe, T.C., Observations and issues on mechanisms of grain refinement during ECAP process. Mater Sci Eng, A291, pp.46-53, 2000.

[4] Iwahashita, Y., Horita, Z., Nemoto, M. \& Langdon, T.G., The process of grain refinement in equal-channel angular pressing. Acta Mater, 46, pp.3317-3331, 1998.

[5] Vinogradov, A., Nagasaki, S., Patlan, V., Kitagawa, K. \& Kawazoe, M., Fatigue properties of $5056 \mathrm{Al}-\mathrm{Mg}$ alloy produced by equal-channel angular pressing. NanoStruct Mater, 11, pp.925-934, 1999.

[6] Pao, P.S., Jones, H.N., Cheng, S.F. \& Feng, C.R., Fatigue crack propagation in ultrafine grained Al-Mg alloy. Inter J Fatigue, 27, pp. 1164$1169,2005$. 
[7] Chung, C.S., Kim, J.K., Kim, H.K. \& Kim, W.J., Improvement of highcycle fatigue life in a $6061 \mathrm{Al}$ alloy produced by equal channel angular pressing. Mater Sci Eng, A337, pp. 39-44, 2002.

[8] Kim, H.K., Choi, M-I., Chung, C.S. \& Shin, D.H., Fatigue properties of ultrafine grained low carbon steel produced by equal channel angular pressing. Mater Sci Eng, A340, pp. 243-250, 2003.

[9] Hanlon, T., Tabachnikova, E. D. \& Suresh, S., Fatigue behavior of nanocrystalline metals and alloys. Inter J Fatigue, 27, pp. 1147-1158, 2005.

[10] Nisitani, H. \& Goto, M., (Eds: Miller, K.J. \& de los Rios, E.R.), A smallCrack Growth Law and its Application to the Evaluation of Fatigue Life. The behaviour of short fatigue cracks, Mech Eng Publications Lim: London pp.461-478, 1986.

[11] Goto, M. \& Nisitani, H., Fatigue life prediction of heat-treated carbon steels and low alloy steels based on a small crack growth law. Fatigue Fract Eng Mater Struc, 17, pp.171-185, 1994.

[12] Goto, M. \& Knowles, D. M., Initiation and propagation behaviour of microcracks in Ni-base superalloy Udime 720 Li. Eng Fract Mech, 60, pp.1-18, 60, 1998.

[13] Goto, M., Han, S.Z., Kim, S.S., Ando, Y. \& Kawagoishi, N., Growth mechanism of small surface-crack of ultrafine grained copper in a highcycle fatigue regime. Scripta Mater, 2009, In press.

[14] Iwahashi, Y., Wang, J., Horita, Z., Nemoto, M. \& Langdon, T.G., Principle of equal-channel angular pressing for the processing of ultra-fine grained materials. Scripta Mater, 35, pp.143, 1995.

[15] Rabkin, E., Gutman, I., Kazakerich, H., Buchman, E. \& Gorui, D., Correlation between the nanomechanical properties and microstructure of ultrafine grained copper produced by equal channel angular pressing. Mater Sci Eng, A396, pp.11-21, 1995.

[16] Valiev, R.Z., Approach to nanostructured solids through the studies of submicron grained polycrystals. NanoStructured Mater, 6, pp.73-82, 1995.

[17] Vinogradov, A. \& Hashimoto, S., Multiscale phenomena in fatigue of ultrafine grain materials-an overview. Mater Trans, 42, pp.74-84, 2000.

[18] Mughrabi, H., Höppel, H.W. \& Kautz, M., Fatigue and microstructure of ultrafine-grained metals produced by severe plastic deformation. Scripta Mater, 51, pp.807-812, 2004.

[19] Goto, M., Han, S.Z., Yakushiji, T., Kim, S.S. \& Lim, C.Y., Fatigue strength and formation behavior of surface damage in ultrafine grained copper with different non-equilibrium microstructures. Inter J Fatigue, 30, pp.13331344, 2008.

[20] Goto, M., Han, S.Z., Yakushiji, T., Lim, C.Y. \& Kim, S.S., Formation process of shear bands and protrusions in Ultrafine grained copper under cyclic stresses. Scripta Mater, 54, pp.2101-2106, 2006.

[21] Nisitani, H., Unifying treatment of fatigue crack growth laws in small, large and nonpropagating cracks, Mechanics of Fatigue -AMD(Ed: Mura, T.), ASME, 43, pp.151-166, 1981. 
[22] Frost, N.E. \& Dugdale, D.S., The propagation of fatigue cracks in sheet specimens. J Mechanics \& Physics Solid, 6, pp.92-110, 1958.

[23] Goto, M. \& Nisitani, H., Inference of a small-crack growth law based on the S-N curves. Trans Jpn Soc Mech Eng, A56, pp.1938-1944, 1990 (in Japanese).

[24] Nisitani, H. \& Goto, M., Kawagoishi, N., A small-crack growth law and its related phenomena. Eng Fract Mech. 41, pp.499-513, 1992. 